\title{
Three sketches for guitar
}

\author{
Mário Aníbal Gonçalves Rego Cardoso
}

Research Center of Basic Education, Polytechnic Institute of Bragança | Portugal

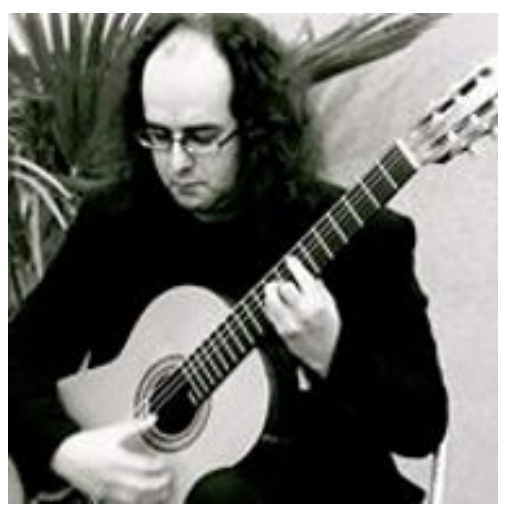

Doctor in Educational Sciences (Music Education) and Master in Music Pedagogy (Classical Guitar). He is Professor at the Higher School of Education of the Polytechnic Institute of Bragança where he works as Coordinator of the Department of Music Education, Director of the Master Degree in Music Education and ViceCoordinator of the Research Center in Basic Education. Develops a regular artistic and investigative activity in the field of Music,

Performing Arts and Music Education. It has numerous publications in these areas, including books, book chapters and articles in national and international journals. He is a member of several international associations and member of the editorial and advisor board in numerous international journals and conferences.

E-mail: cardoso@ipb.pt

ORCID: $\underline{\text { https://orcid.org/0000-0003-3645-9641 }}$ 


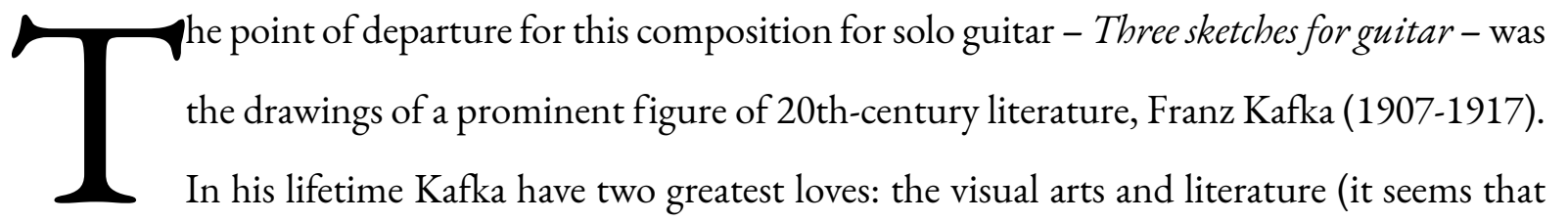
the second might win). The coexistence between these two artistic areas is visible throughout his life. In the early stage, Kafka began filling the margins with sketches in notebooks. In the years at university, he enchanted by the work of Emil Orlik (1870-1932), Jean-Auguste Dominique Ingres (1780-1867) and Vincent Van Gogh (1853-1890). Despite the presence of visual arts in his life, Kafka had a particular vision about his drawings. In the book Conversations with Kafka (2012), Gustave Janouch transcribes a conversation that illustrates the writer's position:

\footnotetext{
You've been drawing? Kafka gave an apologetic smile: "No! These are only doodles.” May I look? As you know, I'm very interested in drawing. But these aren't drawings to be shown to anyone. They are purely personal, and therefore illegible, hieroglyphs. (...) My figures have no proper spatial proportions. They have no horizon of their own. The perspective of the shapes I try to capture lies outside the paper, at the other unsharpened end of the pencil - in myself (JANOUCH, 2012, p. 34)
}

These words reveal that his drawings bring us closer to his most intimate side, as they are his private writing. For this music composition, we inspired in three of his drawings (see Figure 1): The Thinker (1913); Horse and Rider (1917); Three Runners (1912-1913).

FIGURA 1 - Kafka drawings (The Thinker, Horse and Rider and Three Runners).
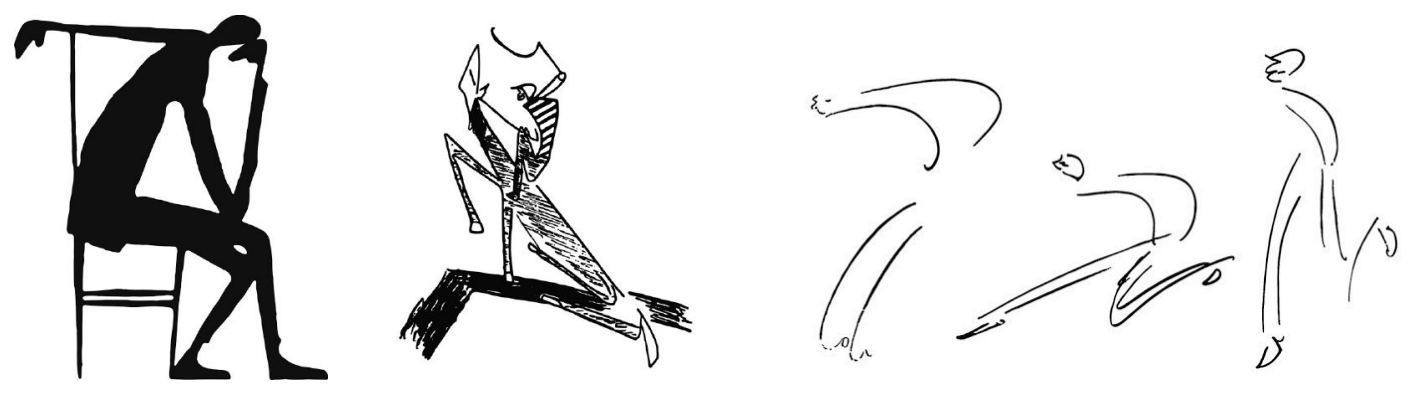

Source: KAFKA (2012)

The composition technique use in these Three sketches for guitar is related to the principles of 20th-century twelve-tone serialism (SCHOENBERG, 1999; BOSS, 2014: WHITTALL, 2008). Throughout the piece, we use the prime series $(\mathrm{P})$ and its various transformations: inversion's $(\mathrm{I})$ or retrograde inversion's $(\mathrm{RI})$. 
FIGURA 2 - Original Row (P).

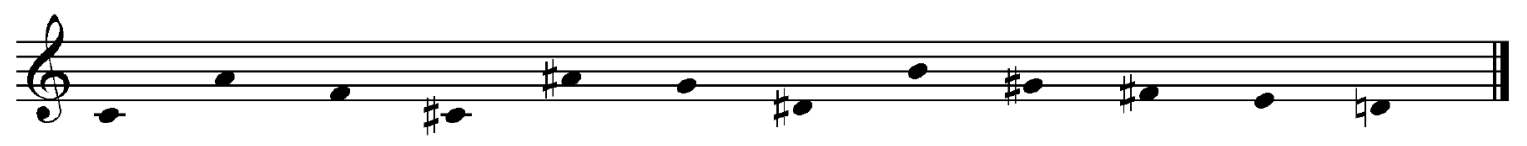

In the first movement of the piece (Largo - The Thinker), the elements that make up the harmonic complexes of the harmonizing series can identify in several orders $\left(\mathrm{P}_{0}, \mathrm{P}_{9}, \mathrm{P}_{10}, \mathrm{P}_{6}\right)$. Rhythmically, the internal sections have different material: dotted half note, quarter note and eighth notes. The second movement (Allegretto - Horse and Rider) use the following transformations of the original row: $\mathrm{I}_{0}$, $\mathrm{P}_{1}, \mathrm{P}_{3}, \mathrm{P}_{5}, \mathrm{P}_{6}$. The rhythmic material is composed, for the most part, by a dotted quarter note, quarter notes and eighth notes, which interact to give rhythmic unity to the movement. Despite the rhythmic unit, there is a wide variation of metric accent, changing between $5 / 8$ and $7 / 8$. The last movement (Agitato - Three Runners) starts with a striking and energetic rhythmic structure that will permeate the whole movement. The alternation between $7 / 8$ and $5 / 8$ underlines this characteristic. The following transformations were used: $\mathrm{RI}_{6}, \mathrm{P}_{3}, \mathrm{RI}_{4}, \mathrm{I}_{7}, \mathrm{RI}_{8}, \mathrm{P}_{0}, \mathrm{RI}_{3}, \mathrm{P}_{2}, \mathrm{I}_{8}, \mathrm{P}_{10}, \mathrm{P}_{11}$.

\section{REFERENCES}

BOSS, J. Schoenberg's Twelve-Tone Music: Symmetry and the Musical Idea. New York: Cambridge University Press, 2014

JANOUCH, G. Conversations with Kafka. New York; New Directions Publishing, 2012.

KAFKA, F. Dibujos de Franz Kafka. Madrid; Sexto Piso, 2012.

WHITTALL, Arnold. The Cambridge Introduction to Serialism. New York: Cambridge University Press, 2008.

SCHOENBERG, A. Fundamentals of Musical Composition. London: Faber \& Faber, 1999. 


\section{Three sketches for guitar}

for solo guitar

Mário Aníbal Gonçalves Rego Cardoso

Agosto de 2020

cardoso@ipb.pt 


\section{Tree sketches for guitar}

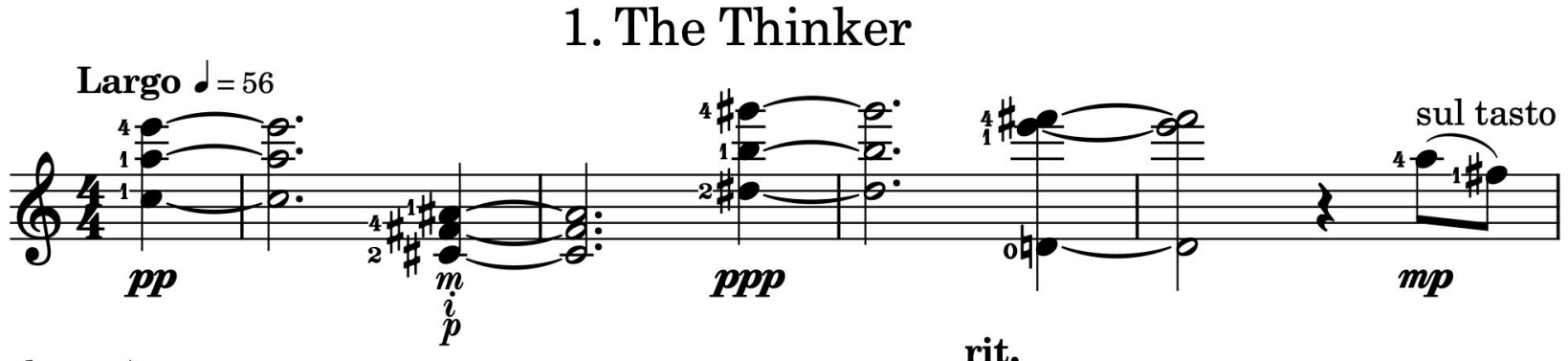

(sul tasto)

rit.
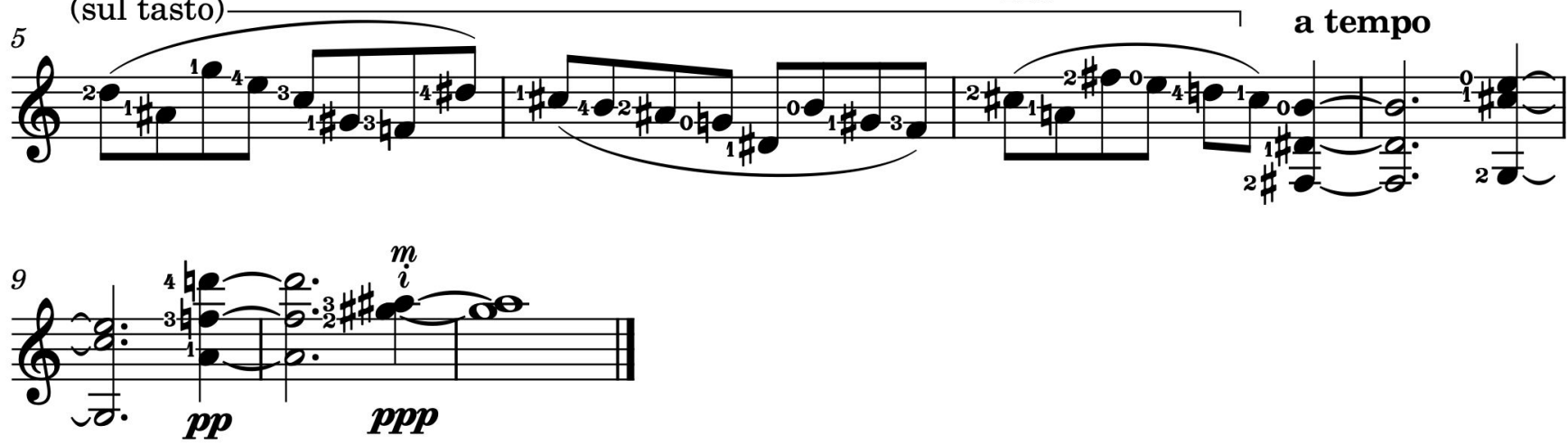

2. Horse and Rider

Allegretto $d=112$

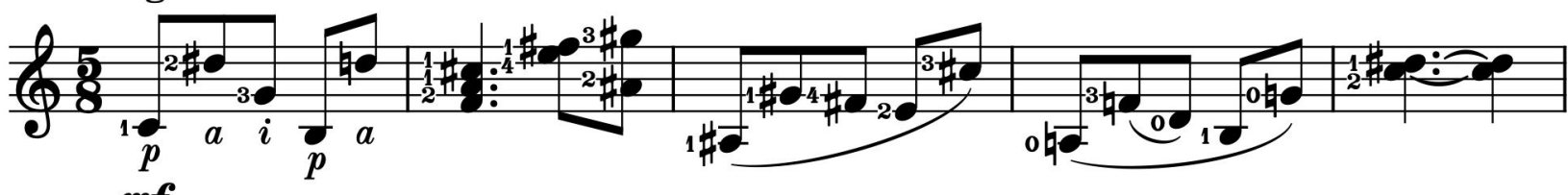

$m f$
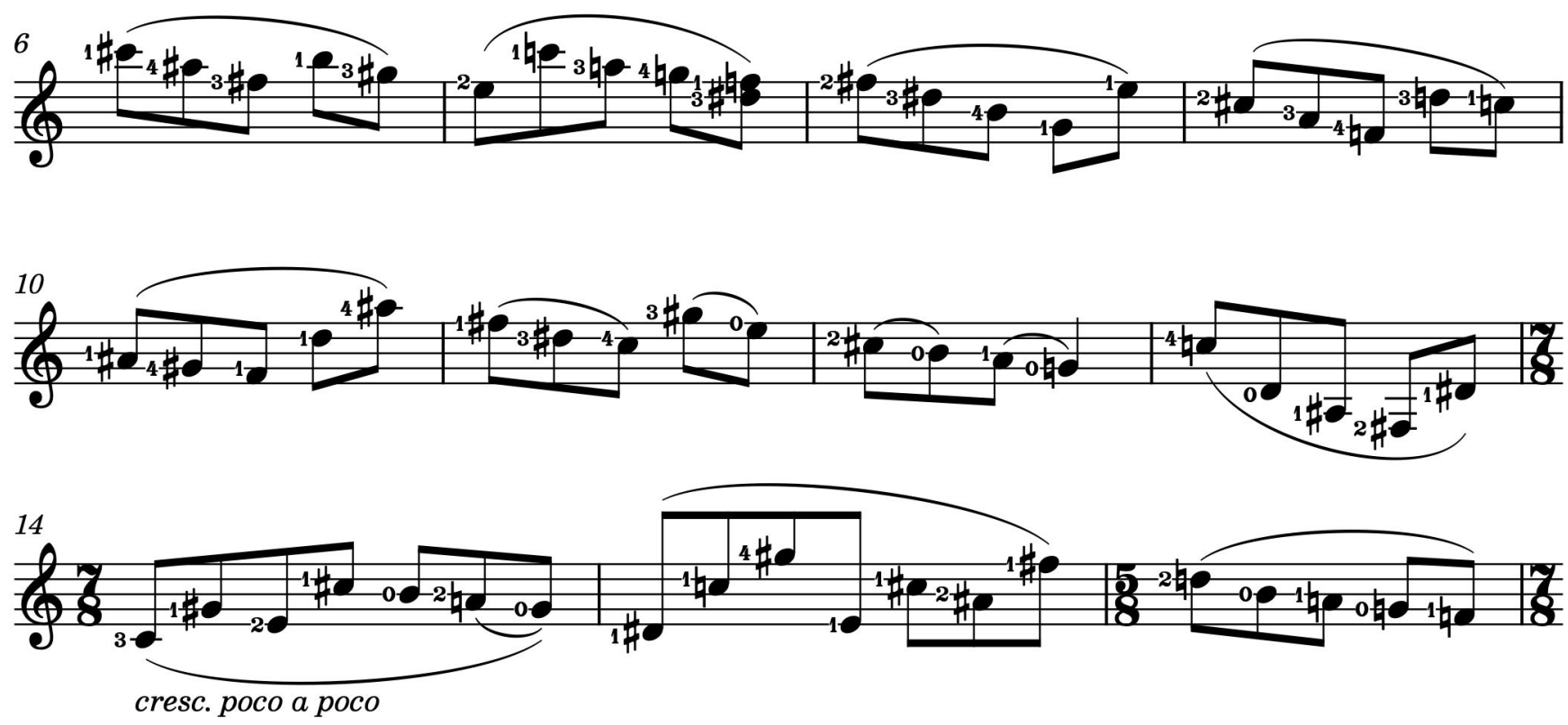
allarg.
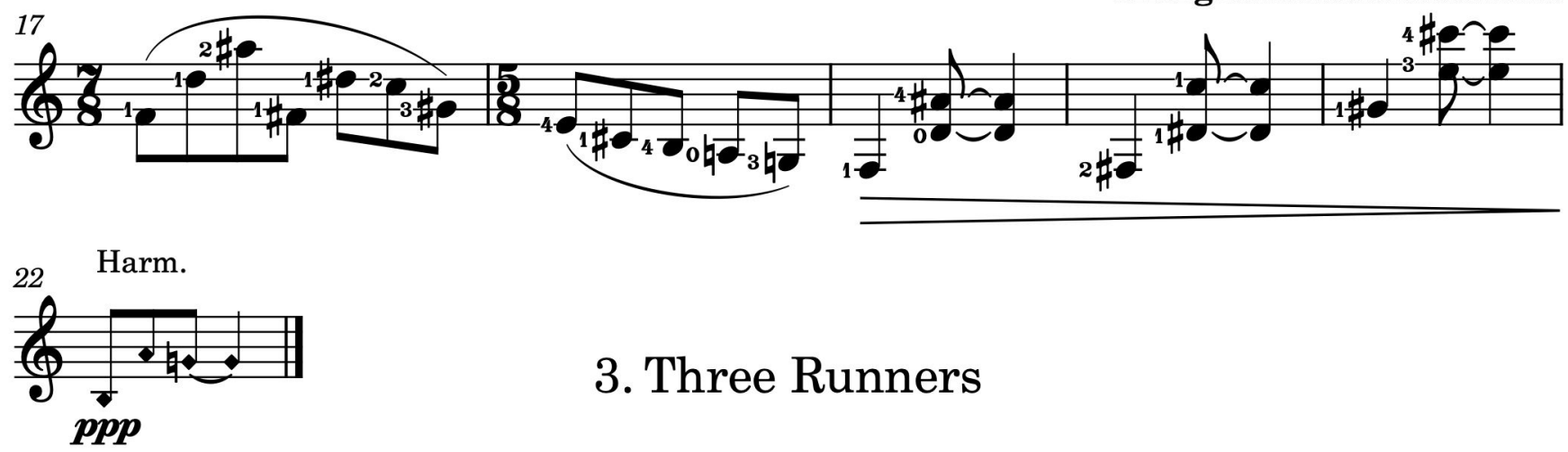

3. Three Runners

Agitato $d=144$
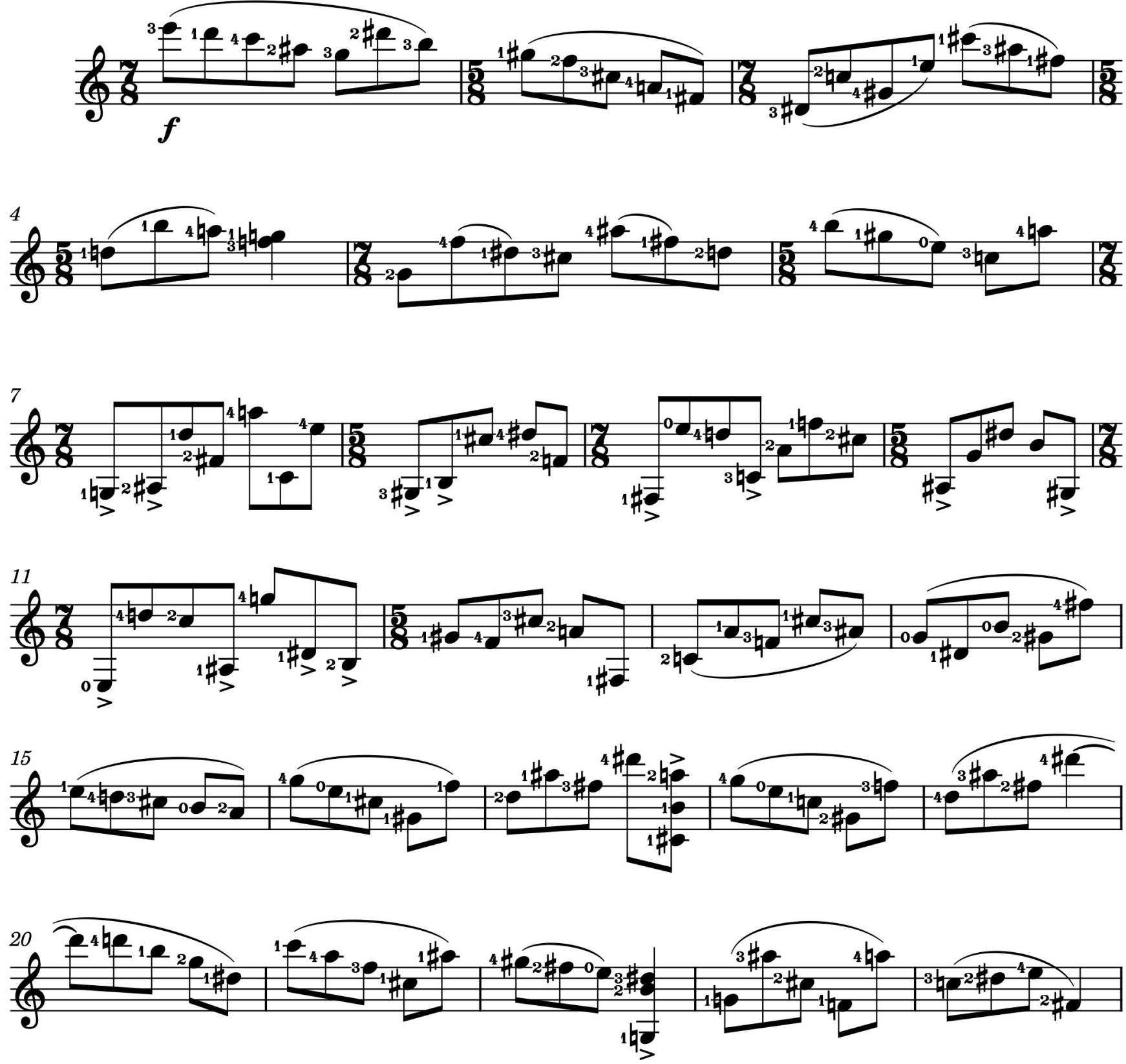

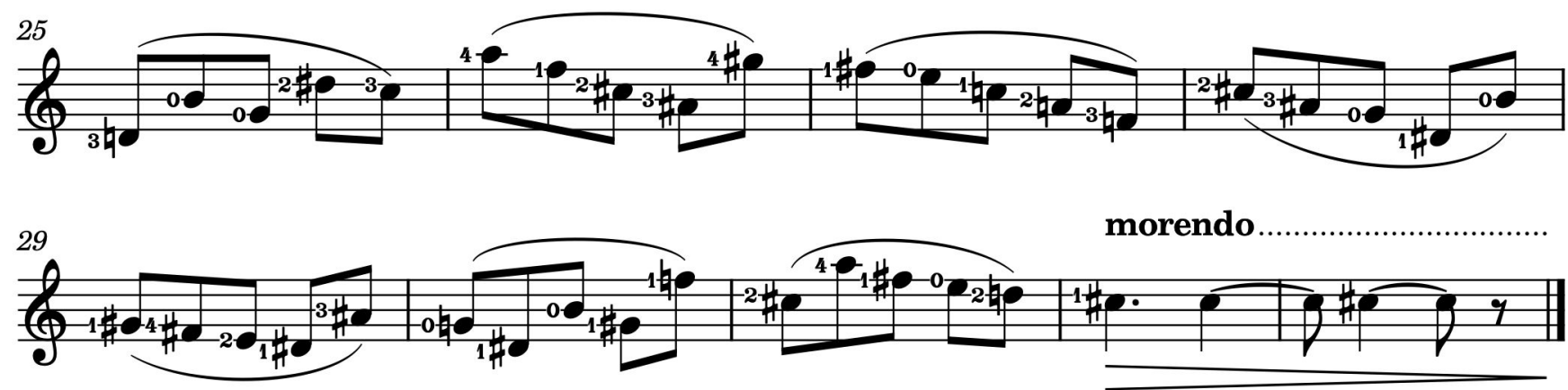